INTERNATIONAL HIGHER EDUCATION Number 71 Spring, 2013

Pages $24-26$

\title{
Central America: The Value of International Academic Cooperation NANETTE SVENSON
}

Nanette Svenson is an adjunct professor at Tulane University's Payson Center for International Development, New Orleans, Louisiana. E-mail: nanette.svenson@gmail.com.

Central America, like many small developing regions, contributes little to worldwide research efforts. It accounts for less than 0.05 percent of global research and development and only 0.07 percent of all Science Citation Index publications. While this would seem to make Central American scientific and technological advances unworthy of study, quite the opposite is true as progress on this front will likely determine the extent of the region's development over the next decades.

Seven countries comprise this subcontinent lying between Mexico and Colombia: Belize, Costa Rica, El Salvador, Guatemala, Honduras, Nicaragua, and Panama. Each is different in many ways, but all fall into the "middle-income" World Bank category of developing countries. So, despite a 40 percent poverty rate, Central America is not poor enough to qualify for most donor aid. Neither is it large or rich enough to generate internally the scientific growth, required for propelling development. Interestingly, more than half of the world's economies fall into the same middling category-almost double the number in either the higher- or lower-income classifications. Thus, the 
circumstances facing Central America, particularly for participation in global scientific exploration, are not unique. International academic cooperation offers a powerful means of addressing this concern and bridging some of the existing gaps.

\section{OBSTACLES}

Central America faces numerous challenges to developing research capacity. Higher education enrollment has increased in recent years—-thanks to a proliferation of private universities and various labor-market financial incentives-and now averages around 25 percent of the age cohort; however, completion rates are estimated at well below half of that. With the exception of Costa Rica, quality is also questionable. No Central American university appears in the international rankings; public investment in education is under the Organization for Economic Cooperation and Development's average 5 percent of gross domestic product; few professors hold advanced degrees; quality-assurance mechanisms are emerging but still underdeveloped; and curricula are generally outdated, overly theoretical, and inapplicable to productive sector work.

Additionally, the region invests little in scientific research. Contrary to its industrialized counterparts, 70 percent of the investment is public, with little to no private support. This represents a considerable limitation, as governments struggle to budget for fundamental health and educational expenses-much less scientific and technological activity. Consequently, research is seen as a luxury, most policymakers are uniformed about its potential returns, and Central America has among the lowest research and development investment rates worldwide. Institutionalization efforts are also lacking, which hinders scientific programming sustainability. Finally, the region 
operates principally in Spanish. This facilitates cooperation within Latin America, but impedes collaboration with North America, Europe, Oceania, and Asia, where the bulk of scientific exploration and publishing is happening.

Even with these obstacles, Central America does have something to offer the global scientific community. Its natural resources, indigenous tradition, and historical migratory importance-among other characteristics-make it a region to study. Its proximity to North America, relative political-economic stability, and literate human capital base also contribute to providing an operational platform. Leveraging these assets to bring education to the point of developing significant scientific capacity is the next step.

\section{Promising INITIATIVES}

International academic cooperation can do much to augment scientific research budgets and build capacity. In fact, international funding currently accounts for nearly 20 percent of Central America's scientific spending. One of the most promising areas in this regard is that of cross-border university- and research institute-led programs. A number of these have been established over the past several decades and are beginning to yield important dividends. This is especially true where collective synergies have been developed, around areas of common regional interest-such as, agriculture, environmental management, and health.

The Tropical Agricultural Research and Higher Education Center (CATIE) in

Costa Rica is one such example. Established over 60 years ago through the InterAmerican Institute of Cooperation on Agriculture and now supported by the World 
Bank and other international donors, CATIE is a regional research and education center, focused on agriculture and natural-resource management. It has graduated more than 2,000 students, operates over 100 research projects, employs professors and researchers from 25 countries, and publishes widely in Spanish and English.

Other examples, similar to CATIE, include the US Smithsonian Tropical Research Institute in Panama; the United Nations University for Peace in Costa Rica; the PanAmerican Health Organization Institute of Nutrition for Central America and Panama in Guatemala; and the Latin American School of Social Sciences, supported by the United Nations Educational, Scientific, and Cultural Organization, with programs throughout the region—including Costa Rica, Guatemala, El Salvador, and Panama. All of these initiatives create regional hubs for specialized knowledge generation, education, research, and innovation in areas critical to Central American development. To the extent they can draw on international scientific research capacity and funding, as well as incorporate regional actors and students, they will continue to advance opportunities for knowledge transfer.

\section{MOVING FORWARD}

Central American governments, at both regional and national levels, must contribute to these efforts more consistently and effectively. Fortifying the national entities responsible for scientific innovation is essential, as is improving monitoring and evaluation methods for producing data on ongoing scientific activity. Costa Rica is farthest ahead with this, followed by Panama and Guatemala, but much remains to be done in all countries. More strategic targeting of specific scientific and technological 
capacities to be developed and the linking of development aims with scientific capacity building are important, too, for better identifying priorities and allocating resources.

Central American universities must also do more to further this process. Even with their limited resources, alignment of graduate studies curricula with research methods that are more reflective of the Frascati principles, used elsewhere as the global benchmark, would represent a solid first step in this direction. Strengthening Englishlanguage skills would complement this effort. Both of these initiatives would better prepare faculty and students to seek out and participate in international research partnerships. Instigating more of the types of international academic cooperation programs, described above, would not only stimulate academic learning in the region but also give universities an added leverage with national governments for increasing research budgets.

Developing Central American scientific and technological capacity is a daunting task. Nevertheless, resources and models are available, and progress is being made in isolated areas. These advances should be nurtured and expanded. Better utilizing international scientific and technological capacity, to further regional development objectives, stands to benefit greatly the countries of Central America. It could also inspire middle-income countries facing similar challenges in other developing regions to do the same. 